\title{
Children's Magic Won't Deliver the Semantic Web
}

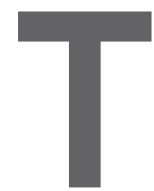

O EXPLAIN THE nature of "Ontologies and the Semantic Web" in his contributed article (Dec. 2008), Ian Horrocks, a leading figure behind the theory and practice of Description Logics (DLs), employed analogous characters and language of the fictional Harry Potter children's novels. Notwithstanding the fact this did not help readers not already familiar with Potter or even those, as there may exist a few, who find the novels utterly boring and repetitive, hearing the same story over again in a new guise prompts me to ask: When will such presentations evolve from toy examples into more realistic accounts of larger, complex ontologies? That is, when will the important issue of scalability in the storage, retrieval, and use of large ontologies (millions of concepts, hundreds of millions of roles/attributes, nontrivial reasoning) be addressed?

Horrocks wrote, "A key feature of OWL is its basis in Description Logics, a family of logic-based knowledgerepresentation formalisms that are descendants of Semantic Networks and KL-ONE but that have a formal semantics based on first-order logic." While this may be true, it could also mislead a neophyte to conclude that DL is somehow the only formalism for representing and using ontologies. This is far from true. There is at least one alternative formalism, also a direct descendant of KL-ONE-Order-Sorted Feature (OSF) constraint logic ${ }^{\mathrm{a}}$ - that lends itself quite well to the task. Elsewhere, I also covered how various DLs and OSF constraint logics formally relate to one another. ${ }^{\text {b }}$

The trouble I see in such publications by influential members of the

a Ait-Kaci, H. Data models as constraint systems: A key to the semantic Web. Constraint Program mingLetters 1 (Nov. 2007), 33-88; www.cs.brown. edu/people/pvh/CPL/Papers/v1/hak.pdf.

b Ait-Kaci, H. Description logic vs. order-sorted feature logic. In Proceedings of the 20th International Workshop on Description Logics. Lecture Notes in Computer Science. Springer-Verlag, 2007; sunsite.informatik.rwth-aachen.de/Publications/CEUR-WS/Vol-250/paper_2.pdf.
World Wide Web Consortium (W3C) is that one particular formalism-DLis being confused with the general issue of formal representation and use of ontologies. It would be like saying Prolog and SLD-Resolution is the only way to do Logic Programming. To some extent, the LP community's insistence on clinging to this "exclusive method" has contributed to the relative disinterest in LP following its development in the 1980s and 1990s. Similarly, DL formalists have built a de facto exclusive reasoning method-Analytic Tableaux-into their formalism so the same causes always result in the same consequences.

Whether the various languages proposed by the W3C are able to fly beyond toy applications has yet to be proved, especially in light of the huge financial investment being poured into the semantic Web. To realize this promise, we must not mistake the tools for the goal. Indeed, while DLs are admittedly one tool among several for representing and using ontologies, the goal is still to make semantic Web ontology languages work, no matter which method is used, as long as it is formal, effective, and efficient on real data. Otherwise, the semantic Web might well end up being built on nothing more than children's magic.

Hassan Aït-Kaci, Vancouver, Canada

\section{Author's Response:}

The Harry Potter example was not intended to be representative of realistic application ontologies. As I discussed in the article, such ontologies are often large and complex, making them unsuitable for didactic purposes.

I certainly didn't mean to suggest that $D L$ is the only possible formal basis for an ontology language. However, it is important to agree on the use of some formalism in order to facilitate the exchange and reuse of ontologies and encourage the development of the tools and infrastructure needed for large-scale ontology development and deployment. This is a major success of RDF and OWL; users now have access to a previously undreamt of range and quality of tools and is a major factor in their popularity.

Finally, the W3C standards relate only to the languages themselves, leaving the design and implementation of tools to developers. The OWL standard does not specify any particular reasoning algorithm, and existing OWL/DL reasoners are based variously on (at least) analytic tableau, resolution, hyper-resolution, query rewriting, saturation, and rule-extended triple stores.

Ian Horrocks, Oxford, U.K.

\section{Give Me the Science of Virtualization, Not Buzzwords}

The "CTO Roundtable on Virtualization, Parts I and II" moderated by Mache Creeger (Nov. and Dec. 2008) was a rambling discussion filled with vague assertions, buzzwords, and brand names but few clear concepts. The anecdotal discussion touched on cloud computing, late binding, even the terror attacks of 9/11, without clear logical sequence or relationship with deeper (unstated) definitions or principles.

As far as I know, VM is an operating system concept first implemented by IBM 40 years ago on its punched-cardera mainframes (360-67) and commercially available on PCs for at least the past 10years. VMwas invented for essentially the same reasons it is used today: run multiple operating systems on one machine in fully isolated ways. Some of these operating systems may be less reliable than others or may still be under test but are unable to interfere with one another. Even if we are talking about the same thing, the roundtable highlighted none of these basic concepts. VM was widely used within a few years of its earliest implementation. One roundtable participant (in Part I, Nov. 2008) said: "I support virtualization." OK, so I support transistor radios.

To me, this is further confirmation of the fact that IT progress is fast on the surface but slow in terms of basic concepts.

Luigi Logrippo, Gatineau, Québec, Canada 


\section{Creeger's Response:}

The CTO Roundtables are conversations, not well-defined treatises with clearcut conclusions. Discussing early-stage adoption of commercial technology involves differences of opinion about definition, best practices, product maturity, and best ways forward. We provide the discussion; the reader decides.

My focus as moderator is commercial benefits and best ways to realize them, conceding that my success varies. Logrippo suggests and I agree we need to do more to extract key ideas and make them more accessible to the reader.

While virtualization goes back more than 40 years, it has gained renewed commercial appeal in the past decade as a better way to provide application services. Overhead, risk, cost, and resulting benefit must be evaluated in the context of the commercial problems being addressed. The goal is not to define virtualization as a new CS technique but address its relatively recent status as an attractive commercial technology. When a panelist supports virtualization, it mean to him its benefits far outweigh its impact on service infrastructure.

Mache Creeger, Head Wrangler, CTO Roundtable Series, Portola Valley, CA

\section{More Legacy from Gates}

Michael Cusumano really knows something about Microsoft, and his Viewpoint column "Technology Strategy and Management" on "The Legacy of Bill Gates" (Jan. 2009) is the best popular assessment I've read on the subject. However, for the public to fully understand how Gates affects the world, three more aspects of that legacy must be understood:

Product lock-in. In the marketplace for everyday consumer software, consumers' decisions are overwhelmed by their need for compatibility with popular file formats; all other desirable attributes, including cost, quality, speed, security, ergonomics, simplicity, size, and feature sets, are simply inactivated by this one imperative. Gates understood this network dynamic at the time he founded Microsoft and has pursued it relentlessly ever since. Never before has a popular world market been so tightly constrained by this idea; billions of consumers have thus been deprived of choices through a single mechanism. Paradoxically, this lock on the market happened even as the technical capacity to produce cheap alternative products mushroomed;

Wheels of justice. As a business calculation, Microsoft ignored a court-imposed fine of one million Euros per day every day for three years. This action (as well as others by Microsoft) created a new level of frustration for court systems and represents a phenomenon of corporate behavior that may now need specific new methods of redress. Speed of compliance with court orders is crucial in a marketplace moving as quickly as IT. As long as the wheels of justice turn slower than marketplace evolution, many laws may be reduced to irrelevance; and

Battle against standards. Microsoft is fully aware that open public standards are an impediment to the perpetuation of its monopolies and spends billions to defeat them. Public standards are a pillar of efficiency in free markets, addressing the lock-in problem by solving the compatibility problems, and hence of immense value to consumers. Unfortunately, the tactics in this battle are largely out of the public's view.

Such business behaviors are only casually understood by the public. None are new, but globalization and the extraordinary new arithmetic of marginal costs in the software industry have intensified their effects. Gates elevated each one to the level of boardroom stratagem, using it to prevent the market from becoming as competitive and productive as it could be. It behooves the world to pay as much explicit attention to these things as Gates did and decide if a response is needed. As economies change, our free-market system requires diligent protection from every scheme that suppresses efficient competition.

\section{J. Stephen Judd, Plainsboro, NJ}

\section{Deserves More Than an Ad Hominem Response}

When columnist Michael Cusumano used the phrase "religious-like responses from the faithful" in his response to a comment (by Ian Joyner, Dec. 2008, concerning his Viewpoint column "Technology Strategy and Management, Sept. 2008) to simply dismiss the comment, it constituted an ad hominem and self-referential attack, not a principled response, and was unworthy of the professional standards ACM is attempting to establish in the new Communications.

Rosemary M. Simpson, Providence, RI

\section{Cusumano's Response:}

It was quite a rude comment to me, and I reacted to the tone of it. No doubt it is best in such cases to wait awhile before responding. But when a reader criticizes every argument by saying I am simply "anti-Apple," there is not much use in replying point by point. I have had many such encounters with Apple users, given my extensive work on Microsoft and concluded there is indeed such a thing as "the Apple faithful" and a strong element of religiousness to them. But I disagree that I am simply anti-Apple. I have been much more critical of Microsoft and Bill Gates. The main point was that I believe Apple could have become the dominant PC technology had Steve Jobs adopted more of an open "platform" strategy, much as Japan Victor did with VHS, which dominated Beta mainly because of the much greater availability of prerecorded tapes (software) and extensive OEM licensing deals (hardware).

Michael Cusumano, Cambridge, MA

Communications welcomes your opinion. To submit a Letter to the Editor, please limit your comments to 500 words or less and send to letters@cacm.acm.org.

Coming Next Month in COMMUNICATIONS

A Direct Path to Dependable Software

Q\&A with Professor Dame Wendy Hall

Computing as a Social Science

The Future of Database Systems and Information Retrieval

The Roofline VisualPerformance Model

And the latest news on active learning, sentiment analysis, and virtual colonoscopy technology. 